\title{
A Time for Argument Theory Integration
}

\author{
J. Anthony Blair \\ Department of Philosophy \\ University of Windsor
}

Published in: (2005) Critical Problems in Argumentation, Charles Arthur Willard (Ed.). Washington, DC: National Communication Association. [Selected papers from the $13^{\text {th }}$ Biennial Conference on Argumentation sponsored by the American Forensics Association and the National Communication Association, Alta, Utah 29 July-2 August, 2003.]

\section{Introduction}

Argument theory has witnessed three decades of remarkable flowering, a proliferation of theoretical insights, and following the Iron Law of Theory Formation, each has been developed in contradistinction to the others. It's not that theorists have been insular. On the contrary, they have for the most part proceeded with a thorough and accurate knowledge of activities in other theoretical gardens besides their own, even borrowing cuttings from one another (for example Walton from Pragma-Dialectics, 1998) or digging together (for example, van Eemeren and Grootendorst with Jackson and Jacobs, 1993). They've exhibited together, every four years, at the Amsterdam theory show. This familiarity, however, has not produced much theoretical integration.

Theoretical integration is not theoretical assimilation. Incompatible theories cannot be assimilated. But what if two apparently conflicting theories turn out to be about different subject matters, and so not incompatible after all? Or what if the claim that a paradigm is mistaken turns out to be better framed as a claim that it has been mis-applied by overenthusiastic (or imperialistic) advocates? What if the reach of a particular theory exceeds its grasp, but within its proper sphere it cannot be seriously faulted? What if an appearance of conflict turns out to be due to a misunderstanding? In such cases, theoretical integration would show how the different theories could cohabit. The result of looking to see how everything fits together might require greater modesty on the part of individual theoretical players, but a more accurate estimate of the extent of their respective theoretical domains.

To be sure, seeing how "everything" fits together is too ambitious a goal for a single short paper. In order to find where opportunities for integration might fruitful, it is useful to look where conflict and incompatibility have been thought to exist. Some of those historical antagonisms include: different conceptions of argument, and of argumentation; formal logic vs. argumentation and informal logic; logic vs. rhetoric vs. dialectic; Pragma-Dialectics vs. informal logic; emotion, intuition and logic. There are certainly others. In this paper I will examine just these antagonisms or ambitions, seeking common ground, or possibilities for coexistence. 


\section{Conceptions of argument}

Twenty-five years ago D.J. O'Keefe $(1977,1982)$ drew to our attention the significance of two very different concepts denoted by the word 'argument.' As it happens, each of the two has several variants, and the Oxford English Dictionary lists another four or five senses of the word. I recently tracked the definitions of O'Keefe's "argument 1 " in about 30 of the formal logic textbooks published since 1950 (reported in Blair, 2003) and found several distinct varieties, including the following three: (a) sets of propositions such that one is implied (or supported) by the others, (b) propositions taken to imply (or support) another, and (c) propositions offered in support of a claim. The first makes no reference to human judgement or intention but the other two do. The second makes such an argument out to require human intention, but not communication. The third requires both intention and communication. Which of the three is the correct conception of argument ${ }_{1}$ ?

The answer I suggest is: any of them. It depends on one's interests. If you are interested in the syntactic or semantic implication relationships among propositions, then what's of interest to you are simply groups of propositions. Those relationships obtain whether or not anyone thinks of them or knows about them. There is a tradition in which such implication-related proposition sets are called arguments, but in that case, you are talking about something different from arguments understood as what people take to be reasons why something is true or something should be done, which is also a sense of 'argument' with a tradition of use behind it. Both these senses are different from the third, because one person can offer another person reasons for believing something or doing something that don't imply or otherwise support it and that the arguer doesn't think support it either. Yet this too is something widely called an argument. To my knowledge, there is no good reason for assigning a privileged status to one of these senses over the other two. The argument theorist might want to pick one for some theoretical purpose or another. One could in principle determine empirically their respective frequencies of use, but to what purpose?

\section{Argumentation}

The word 'argumentation' has many meanings in English too, but the one that has acquired currency in argumentation theory is "a discussion dealing with a controversial point" (Random House Dictionary, 1967), especially if it involves the use of arguments. The theorists here stipulate different definitions. As stipulations one can perhaps have no quarrel with them, however, they have a way of eliding into what Stevenson dubbed "persuasive definitions"(1944). For example, van Eemeren and Grootendorst are quite careful to insist that the definition of argumentation that they give in their groundbreaking 1984 book is a stipulation (see 1984, 18, and endnote 10), but by the time of their introduction (with Snoeck Henkemans) to their 1996 review of the literature anthology, they say, without qualification that "the general characteristics of argumentation are ... recapitulated in the following definition:"

Argumentation is a verbal and social activity of reason aimed at increasing (or decreasing) the acceptability of a controversial standpoint for the listener or reader, 
by putting together a constellation of propositions intended to justify (or refute) the standpoint before a rational judge. $(1996,5)$

Here is the epistemologist Alvin Goldman's take on "argumentation” (1999, p. 131):

If a speaker presents an argument to an audience, in which he asserts and defends the conclusion by appeal to the premises, I call this activity argumentation. More specifically, this counts as monological argumentation, a stretch of argumentation with a single speaker. Later I shall also discuss dialogical argumentation, in which two or more speakers discourse with one another, taking opposite sides of the issue over the truth of the conclusion.

And here is the informal logician Ralph Johnson's account (2000, p. 12):

By "the practice of argumentation," I understand the sociocultural activity of constructing, presenting, interpreting, criticizing, and revising arguments. (p. 12)

Goldman criticizes Pragma-Dialectics as focussed on producing rational agreement, but inadequate to optimize truth (Goldman, 1999, 160). As avowed Popperians, van Eemeren and Grootendorst would, I expect, take issue with Goldman's veritistic epistemology. Johnson questions whether the Pragma-Dialectical rules guarantee the kind of manifest rationality that he espouses, which can require giving arguments even if one's interlocutor doesn't require them (Johnson, 2000, pp. 309-320).

But why should Goldman or Johnson criticize the Pragma-Dialectical conception of argumentation? Goldman's interest lies in a procedure that transmits knowledge and maximizes true belief. Johnson's interest lies in a procedure that ensures evidently or manifestly rational persuasion. And van Eemeren and Grootendorst are interested in a procedure that resolves disagreements in a way that satisfies constraints of procedural rationality. Each defines argumentation to suit his theoretical goals, and there is nothing wrong with that. The mistake occurs when any one of them criticizes the others' definitions for failing to be based on his theoretical preoccupations - in other words, when any one of them proclaims his definition as the correct or the one and only adequate definition of argumentation. None of these theorists makes the case that his is the only correct conception of argumentation.

\section{Formal logic and argument}

At the beginning of their current era of flourishing, both the speech communication and the informal logic orientations to argument and argumentation attacked logic, or formal logic. Scriven asserted that the emergence of informal logic, "marks the end of the reign of formal logic. Not by any means the end of the subject, just its relegation to its proper place in the academic zoo, somewhere over just north of mathematics and west of computer science ... " (1980, p. 147). Willard likened the relation between propositional or syllogistic logic to actual arguments to the relation between a nineteen-legged French Provincial table to an ordinary four-legged table (1983, pp. 29-30). These are amusing 
comments, and typical of the revolt against formal logic that occurred in the 1960s and 1970s. The vigor of the vituperation suggests that those making the criticisms might have been exorcising their own demons.

I don't mean to suggest that the critique of the hegemony of deductive logic was mistaken, but the problem is not with logic. It lies in taking logic to be the normative theory of argument. Most logicians, when practising their craft, focus on the purely formal properties of logical systems, leaving the applications of those systems to others. Some argumentation theorists retain a central role for deductive implication relationships. The Pragma-Dialecticians $(1984,1992)$ have opted for deductive reconstruction in the analysis of arguments, and Groarke $(1995,1999)$ has been arguing for something similar-what I call "methodological deductivism." They treat arguments as if they are supposed to be deductively valid and reconstruct them on that assumption, thus finessing the problem of having to deal with premise-conclusion relationships for which no theoretical account yet exists. Whether or not that approach leads to overlooking whole classes of arguments, as Govier $(1987,1999)$ and Walton (1996) have contended, is a debate that can be carried on within the argumentation community without disparaging formal logic. Also, other norms besides deductive validity, or even deductive validity and inductive strength, no longer have to struggle for recognition. Logicians have recognized that dialectic and rhetoric introduce essential perspectives. The idea that arguments can be adequately analyzed and evaluated outside the contexts or situations of their use is more or less dead among all but the most isolated philosophers and logicians. And deductive logic, in the service of computer modelling and artificial intelligence, has itself changed so much over this period that non-monotonic logics that can model the flexibility and ceteris paribus character of the situated inferences of actual reasoning and arguments are at the cutting edge of logical theory.

The upshot is that argument theory is now robust enough to tolerate old-fashioned deductive logic, and contemporary deductive logic has adapted itself to the imperatives of argument theory. The antagonism of argumentation theorists towards formal logic should be a thing of the past.

\section{Logic, rhetoric and dialectics}

A certain amount of pushing and shoving goes on among the adherents of a logic-first approach, a dialectic-first approach and a rhetoric-first approach to argument analysis and evaluation. The Pragma-Dialectical school takes dialectics to be primary, rhetoric as strategic manoeuvring in dialectical interactions, and logic as a contribution to rational dialectic. Tindale suggests that rhetoric is foundational $(1999$, p. 18) - that argument is at root rhetorical, and dialectic and logic supervene upon it. Johnson (2000) takes logic to be fundamental, dialectic to complete it, and rhetoric to serve it. They cannot all be right, but they can all be wrong. I think Wenzel (1990) was right: each of logic, dialectic and rhetoric is an essential perspective on, or aspect of argument, with none more important than the others.

Here's why. Apart from quarrels, there can be no argument without a reference to reasons (cf. Jacobs, 2000, p. 264). Even the Monty Python disputes- "It is. / No it isn't. / Yes it is." and "I did. / No you didn't. / Yes I did."-give way to, "Prove it. / No, you 
prove it." Whenever the reasons are identified, one can ask: What kind and strength of support do they offer? The answer comes from some theory of logic, if logic is understood to include the theory of cogent support. So, no argument without logic. Yet most argument occurs in the context of exchanges between contending parties, or occupants of contending roles, and one can ask whether such exchanges are well ordered. The answer comes from some theory of dialectic. So, almost no argument without dialectic. Finally, at least for argument considered as a tool of attitude-change, the exercise of the art of presentation is inescapable from the advocate's perspective, as it is no less from the perspective of the interpreter of the advocacy, or of its critic. Moreover, considering argument as particular type (or collection of types) of communication, all the resources of the art and craft of communication have application to it. Rhetoric, either in its narrower or its wider characterizations, is the name of these arts. So, no argument without rhetoric.

If it be argued that since one must take the rhetorical perspective in order accurately to interpret the logic of someone's argument, rhetoric is basic to logic (see Tindale, 1999), I would reply that what originally motivates the hunt is the logic, sine qua, non; so, by parity of reasoning, logic is basic. Similar arguments refute the claims to primacy of dialectic and of logic. Grant that all arguments, including monological ones, can be modelled as dialogical exchanges; even so, what makes those dialogues argumentative exchanges, as distinct from, say, chat exchanges-"Nice day."/ "Sure is."-is that the turn-takers offer up reasons for their claims, reasons purported and expected to pass some test of minimal logical adequacy. And to turn the point around, the appeal to logic in argumentation is made in the service, typically, of responses to dialectical challenges, carried out in a way that achieve the arguer's wider communicative goals and (perhaps) narrower persuasive objectives.

\section{Pragma-Dialectics and informal logic}

Johnson (2000) thinks informal logic competes with Pragma-Dialectics, which he discusses in a section titled, "Alternative Theories" (see pp. 309-320). But over the years, theorists who self-identify as informal logicians (such as Walton, and Johnson himself) have tended to agree with the Pragma-Dialecticians that informal logic's focus is as much pragmatic as logical (indeed, Johnson subtitles his book, "A pragmatic theory of argument"), and that argument is typically and deeply dialectical (see Blair and Johnson's early article, 1987). While informal logicians have approached the identification and interpretation of arguments without a theoretical underpinning like speech-act theory, they haven't held that the Pragma-Dialectical use of speech-act theory is mistaken. I've noted that some informal logicians argue against the need for deductive-reconstruction in interpreting. For instance, Walton (1996), Govier (1999), Pinto (2001), and Blair (1999, 2001), have variously proposed that there are legitimate patterns of argument that such a reconstruction would distort. This disagreement, however, is not a deep opposition between contending theories. Nothing prevents someone committed to a pragmadialectical approach in general, and to all other details of the official Pragma-Dialectical theory, from suggesting a revision in line with the views of these informal logicians. It is true that one or two of the famous ten Pragma-Dialectical commandments (van Eemeren 
\& Grootendorst, 1992) would have to be modified, as would some details of the theory's prescriptions for explicitizing unexpressed premises, since those prescriptions rely on the theory's methodological deductivism (see van Eemeren and Grootendorst, 1984, Ch. 6), but those changes would not be incompatible with the spirit of the pragma-dialectical project.

Another apparent source of disagreement between some informal logicians and Pragma-Dialectics is the latter's working assumption that all arguments can most fruitfully be analyzed as approximations of the Pragma-Dialectical ideal model. Blair (1998) and Govier (1999) take issue with this view. However, there is nothing particularly associated with informal logic behind dissent from the universal applicability of the Pragma-Dialectical model. Presumably for proponents of Pragma-Dialectics themselves there is no a priori commitment to its universal applicability, for otherwise the theory would have become an ideology rather what it is expressly presented as, namely a valid normative/descriptive theory. So the extent of its applicability must be an open question even from within the theory.

\section{Emotion, intuition and logic}

In Coalescent Argumentation (1997), Gilbert takes aim at logic, formal and informal, as hostile to emotion and intuition as modes of argument. Part of his target is the practice of decontextualizing argument, leaving out of account both the fact that so-called "claims" are almost always but fragments of or abstractions from an interconnected complex of views better understood as a position (see pp. 105-106), and positions attached to individual persons - a point made by Willard a decade earlier, 1989, pp. 63-64.) For example, being opposed to abortion on demand usually doesn't stand independently of a world-view. Part of Gilbert's target is the view that reason is incompatible with emotions and feelings. Surely Juan's deep and exclusive love for Amelia is a good reason why she should marry him (see "emotional" mode, pp. 82ff.) and getting a creepy feeling from being in it is surely a good reason for not buying a house (see "kisceral" mode, pp. 86ff.). Gilbert contends that any logic rejects such arguments.

The advice that particular arguments be situated in the contexts of their interlocutors' attitudes is well taken. But informal logic from its inception pressed for looking at reallife arguments in their contexts (see Johnson \& Blair, 1980). As for emotions and feelings, the fact that such reasons don't strictly entail the judgements grounded on them is, for informal logic, certainly no bar against such reasoning, or arguments invoking it. Moreover, current theories of practical reasoning do not reject emotions and feelings as irrational or as otherwise illegitimate as reasons for actions (e.g., Audi, 1989). In philosophical discussions of emotions for many years now the Hume/Kant dichotomy between reason and emotion or feeling has been rejected (see Solomon 1977, de Sousa 1987). So here is another "disagreement" that dissolves upon examination.

\section{Conclusion}

There is much more to be said, but if the thesis of this paper is correct, then there is less 
disagreement and theoretical conflict on the current argumentation scene than some have thought. In some cases, apparently conflicting conceptions are just different; in some cases what have been taken to be conflicts between theories are disagreements, sure enough, but not clashes of deep theoretical perspective; in some cases perceived incompatibilities are compatible. I have tried no more than to illustrate a few ways in which argument theory integration might be carried out in order to encourage others to take up the challenge and do the job properly. 


\section{References}

Audi, R. (1989). Practical Reasoning. London and New York: Routledge.

Blair, J.A. (1998). The limits of the dialogue model of argument. Argumentation 12: 325339.

Blair, J.A. (1999). Presumptive reasoning/argument: An overlooked class. Protosociology, Special Issue on Argumentation and Reasoning, ed. by Dieter Mans.

Blair, J.A. (2001). Walton's argument schemes for presumptive reasoning: A critique and development. Argumentation 15: 365-379.

Blair, J.A. (2003, forthcoming). "Argument' and 'logic' in philosophy. In H.V. Hansen \& C.W. Tindale (eds.), Argument and its applications, Proceedings of 2001 OSSA conference. Windsor: Informal Logic, CD-ROM

Blair, J.A. and R.H. Johnson. (1987). Argumentation as dialectical. Argumentation 1: 4156.

Eemeren, F.H. van and R. Grootendorst. (1984). Speech acts in argumentative discussions. Dordrecht: Foris.

Eemeren, F.H. van and R. Grootendorst. (1992). Argumentation, Communication and Fallacies. Hillsdale, NJ: Lawrence Erlbaum Associates.

Eemeren, F.H. van, R. Grootendorst, S. Jackson and S. Jacobs. (1993). Reconstructing argumentative discourse. Tuscaloosa and London: University of Alabama Press.

Eemeren, F.H. van, R. Grootendorst, A.F. Snoeck Henkemans, Eds. (1996). Fundamentals of argumentation theory. Mahwah, NJ: Lawrence Erlbaum Associates.

Gilbert, M.A. (1997). Coalescent argumentation. Mahwah, NJ: Lawrence Erlbaum Associates.

Goldman, A.I. (1999). Knowledge in a social world. Oxford: Clarendon Press.

Govier, T. (1987). Problems in argument analysis and evaluation. Dordrecht: Foris.

Govier, T. (1999). The philosophy of argument. Newport News, VA: Vale Press.

Groarke, Leo. (1995). What pragma-dialectics can learn from deductivism, and what deductivism can learn from pragma-dialectics. In F.H. van Eemeren, R. Grootendorst, J.A. Blair, C.A. Willard (eds.), Analysis and evaluation, Proceedings of the $3^{\text {rd }}$ ISSA conference on argumentation, pp. 138-145. Amsterdam: SicSat.

Groarke, Leo. (1999). Deductivism within Pragma-Dialectics. Argumentation 13: 1-16.

Jacobs, S. (2000). Rhetoric and dialectic from the standpoint of normative pragmatics. Argumentation 14: 261-286.

Johnson, R.H. (2000). Manifest rationality, A pragmatic theory of argument. Mahwah, NJ: Lawrence Erlbaum Associates.

Johnson, R.H. \& J.A. Blair. 1980. The recent development of informal logic. In J.A. Blair and R.H. Johnson (eds.), Informal logic, The first international Symposium. pp. 3-28. Inverness, CA: Edgepress.

O'Keefe, D.J. (1977). Two concepts of argument. Journal of the American Forensic Association 13: 121-128.

O'Keefe, D.J. (1982). The concepts of argument and arguing. In J.R. Cox and C.A. Willard (eds.), Advances in argumentation theory and research, pp. 3-23. Carbondale and Edwardsville: Southern Illinois University Press.

Pinto, R.C. (2001). Argument, inference and dialectic. Dordrecht: Kluwer Academic Publishers. 
Random House dictionary of the English language. (1967). Unabridged edition. New York: Random House Inc.

Scriven, M. (1980). The philosophical and pragmatic significance of informal logic. In J.A. Blair and R.H. Johnson (eds.), Informal logic, The first international Symposium. pp. 147-160. Inverness, CA: Edgepress.

Solomon, R.C. (1977). The passions, The myth and nature of human emotion. Garden City, NY: Anchor Press/Doubleday.

Sousa, R.de.(1987). The rationality of emotion. Cambridge: The MIT Press.

Stevenson, C.L. (1944). Ethics and language. New Haven: Yale University Press.

Tindale, C.W. (1999). Acts of arguing. Albany: State University of New York Press.

Walton, D.N. (1996). Argumentation schemes for presumptive reasoning. Mahwah, NJ: Lawrence Erlbaum Associates.

Walton, D.N. (1998). The new dialectic, Conversational contexts of argument. Toronto: University of Toronto Press.

Wenzel, J.W. (1990). Three perspectives on argument: Rhetoric, dialectic and logic. In R. Trapp and J. Schuetz (eds.), Perspectives on argumentation, Essays in honor of Wayne Brockriede, pp. 9-26. Prospect Heights, IL: Waveland Press.

Willard, C.A. (1983). Argumentation and the social grounds of knowledge. Tuscaloosa: University of Alabama Press.

Willard, C.A. (1989). A theory of argumentation. Tuscaloosa and London: University of Alabama Press. 